\title{
BMJ Open Association between multiple symptoms and quality of life of paediatric patients with cancer in Brazil: a cross-sectional study
}

\author{
Sandra de Andrade Cadamuro, ${ }^{1}$ Julia Onishi Franco, ${ }^{1}$ Carlos Eduardo Paiva, ${ }^{1,2}$ \\ Marco Antonio de Oliveira, ${ }^{1}$ Bianca Sakamoto Ribeiro Paiva (D) ${ }^{1}$
}

To cite: de Andrade

Cadamuro S, Onishi Franco J, Paiva CE, et al. Association between multiple symptoms and quality of life of paediatric patients with cancer in Brazil: a cross-sectional study. BMJ Open 2020;10:e035844. doi:10.1136/ bmjopen-2019-035844

- Prepublication history for this paper is available online. To view these files, please visit the journal online (http://dx.doi org/10.1136/bmjopen-2019035844).

Received 18 November 2019 Revised 26 March 2020 Accepted 03 April 2020

\section{Check for updates}

(c) Author(s) (or their employer(s)) 2020. Re-use permitted under CC BY-NC. No commercial re-use. See rights and permissions. Published by BMJ.

${ }^{1}$ Learning and Research Institute, Barretos Cancer Hospital, Barretos, Brazil ${ }^{2}$ Department of Clinical Oncology, Barretos Cancer Hospital, Barretos, Brazil

Correspondence to Dr Bianca Sakamoto Ribeiro Paiva; bsrpaiva@gmail.com

\section{ABSTRACT}

Objectives To identify the association of multiple symptoms and clinical characteristics on quality of life (QoL) of paediatric patients with cancer.

Design A descriptive, cross-sectional study.

Setting South American Children's Hospital for Cancer Treatment (Barretos, São Paulo, Brazil).

Participants A total of 157 participants, 116 paediatric patients, diagnosed with cancer, undergoing chemotherapy treatment, between 7 and 18 years of age and 41 proxies for patients between 2 and 6 years of age.

Primary outcome measures The severity and prevalence ofsymptoms were identified through the use of a culturally adapted multi-symptomscreening tool, and the influence these symptoms, in association with clinicalcharacteristics, had on the QOL of Brazilian pediatric cancer patients wasassessed.

Results Prevalent symptoms identified by all participants were 'feeling tired' $(98,62.4 \%)$, 'feeling more or less hungry (do not feel like eating) than you usually do' (96, $61.1 \%)$, 'changes in taste (flavour of the food)' (89, $56.7 \%$ ), 'throwing up or feeling like you may throw up' $(77,49 \%)$ and 'changes in how your body (visually) or face looks' (72, $45.9 \%)$. The multivariate analysis for symptom severity as reported by proxies showed that surgery $(0 \mathrm{R} 0.20,95 \% \mathrm{Cl}$ 0.04 to $0.98, \mathrm{p}=0.047$ ) and time of diagnosis ( $0 \mathrm{R} 0.14$, $95 \% \mathrm{Cl} 0.03$ to $0.66, p=0.012$ ) were associated with a decreased $\mathrm{OR}$ of high severity symptoms.

An analysis of the clinical characteristics associated with Pediatric Quality of Life Inventory (PedsQL) demonstrated no significant effect on QoL in any of the domains evaluated. The association between Symptom Screening in Pediatrics Tool and PedsQL in the self-report version demonstrated a significant negative influence of all symptoms on the QoL.

Conclusions The prevalence of symptoms experienced among pediatric patients during treatment was high and significantly influenced all aspects of quality of life,especially in the emotional domain.

\section{INTRODUCTION}

In recent years, there has been an increase in the cancer cure rate resulting in a higher survival rate. However, some children experience severe physical symptoms related to the

\section{Strengths and limitations of this study}

- This study was conducted using a recently validated and reliable symptom screening scale Symptom Screening in Pediatrics Tool, developed for the Brazilian Portuguese speaking paediatric population.

- A longitudinal study and complete assessment of the changes of symptoms on QoL was not performed.

- The study was conducted in a single reference centre of paediatric oncology in Brazil that provides care to patients of regions of the country.

- The analysis of each patient was completed regardless of the stage of treatment.

disease and treatment. ${ }^{1}$ Indeed, symptoms are among the most prevalent problems in paediatric patients with cancer and contribute to a significant worsening of quality of life (QoL). ${ }^{23}$

In a study on the assessment of symptom prevalence. Collins et at reported that the most prevalent symptoms among paediatric patients with cancer between 7 and 18 years of age to be vomiting, coughing, lack of appetite, pain, nausea, a lack of energy, irritability and anxiety. Another study found that physical symptoms as perceived by parents, are the most distressing and produce a high level of suffering among their children. ${ }^{5}$

The presence of multiple distressing symptoms has a direct effect on QoL. ${ }^{67}$ QoL can be defined as a subjective assessment of an individual's concept of their own health as well as the influence symptoms have on his/ her life and are related to different physical, functional, psychological and social aspects. Therefore, an assessment of QoL becomes increasingly important in the clinical practice of paediatric cancer treatment. ${ }^{8-10}$

Assessing the aspects that compromise the life of a patient as a result of disease and treatment, such as prevalent symptoms in addition 
Table 1 Demographic and clinical characteristics $(n=157)$

\begin{tabular}{|c|c|c|c|c|}
\hline \multirow[b]{3}{*}{ Characteristics } & \multirow{2}{*}{\multicolumn{2}{|c|}{$\begin{array}{l}\text { Self-reported } \\
\text { version }\end{array}$}} & \multirow{2}{*}{\multicolumn{2}{|c|}{$\begin{array}{l}\text { Proxy-reported } \\
\text { version } \\
\text { Frequency }\end{array}$}} \\
\hline & & & & \\
\hline & $\mathbf{n}$ & $\%$ & $\mathbf{n}$ & $\%$ \\
\hline \multicolumn{5}{|l|}{ Sex } \\
\hline Male & 72 & 62.1 & 6 & 14.6 \\
\hline Female & 44 & 37.9 & 35 & 85.4 \\
\hline \multicolumn{5}{|l|}{ Race } \\
\hline White & 60 & 52.6 & 13 & 31.7 \\
\hline Black & 10 & 8.8 & 6 & 14.6 \\
\hline Mixed & 42 & 36.8 & 22 & 53.7 \\
\hline Asian & 2 & 1.8 & 0 & 0 \\
\hline \multicolumn{5}{|l|}{ Primary tumour } \\
\hline Solid & 65 & 58.0 & 20 & 48.7 \\
\hline Haematological & 43 & 38.4 & 17 & 41.4 \\
\hline $\begin{array}{l}\text { Central nervous } \\
\text { system }\end{array}$ & 4 & 3.6 & 2 & 4.8 \\
\hline $\begin{array}{l}\text { Without defined } \\
\text { diagnosis }\end{array}$ & - & - & 2 & 4.8 \\
\hline \multicolumn{5}{|l|}{ Distant metastasis } \\
\hline No & 86 & 75.4 & 31 & 75.6 \\
\hline Yes & 28 & 24.6 & 10 & 24.4 \\
\hline \multicolumn{5}{|l|}{ Treatment performed } \\
\hline Chemotherapy & 116 & 100.0 & 41 & 100.0 \\
\hline $\begin{array}{l}\text { Chemotherapy } \\
\text { and radiotherapy }\end{array}$ & 14 & 12.1 & 1 & 2.4 \\
\hline $\begin{array}{l}\text { Chemotherapy } \\
\text { and surgery }\end{array}$ & 33 & 28.4 & 14 & 34.1 \\
\hline Transplant & - & - & 1 & 2.4 \\
\hline \multicolumn{5}{|l|}{ Amputation } \\
\hline No & 106 & 93.8 & 40 & 97.6 \\
\hline Yes & 7 & 6.2 & 1 & 2.4 \\
\hline
\end{tabular}

to clinical characteristics presented during treatment, may enable targeted interventions and contribute to improving the outcome of therapeutic interventions. ${ }^{11}$ Thereby positively impacting QoL. Thus, routinely assessing QoL and multiple symptoms reported by patients themselves in clinical practice should be included in care protocols. ${ }^{9}$

The patient self-report is still the most reliable for symptom assessment, as it provides information that is unique and precise to the patient's actual condition. In a systematic review of existing symptoms scales available in English for the assessment of symptoms in children and adolescents undergoing cancer treatment, found that the use of self-reporting symptoms scales proved to be extremely useful and promising for the identification of symptoms and symptom severity in clinical studies. ${ }^{12}$ Nonetheless, in cases where it is impossible for a patient to self-report due to age or health condition, evaluation by proxies (parents or guardians) becomes an essential alternative. $^{13}$
Currently, there are different instruments for assessing individual symptoms available in Brazil for the use in paediatric patients. ${ }^{14}{ }^{15}$ However, a screening tool for multiple symptoms had not been available for the Brazilian Portuguese speaking population. The Symptom Screening in Pediatrics Tool (SSPedi-BR), has been recently developed and validated for the screening of multiple symptoms, for the benefit of the Brazilian paediatric population with cancer. It has the ability to evaluate fifteen symptoms easily and quickly, taking an average of only 3 min to complete. ${ }^{16-18}$

There are measurement instruments that are valid and reliable that can be used to assist patients and proxies in the evaluation of QoL constructs and symptoms. To assess the QoL of paediatric patients, the Pediatric Quality of Life Inventory (PedsQL) ${ }^{19}$ which has been validated for the Brazilian population, is divided by age group and widely used in clinical practice. ${ }^{20}$

The use of these instruments, SSPedi-BR and PedsQL may facilitate or impact the routine evaluation during clinical practice, resulting in the identification of symptoms and clinical characteristics that have a negative effect on the QoL of paediatric patients with cancer in Brazil. In this context, the aim of this study was to evaluate an association of prevalent symptoms and clinical characteristics on the QoL of paediatric patients with cancer treated at a reference hospital in Brazil.

\section{METHODS}

\section{Study design}

This was a descriptive, cross-sectional study resulting from a subanalysis of a study validating the scale screening of symptoms among paediatric patients with cancer (SSPedi), denominated in Brazil as SSPedi-BR. ${ }^{18}$

\section{Participants and eligibility criteria}

The study included patients between 7 and 18 years of age and proxies (parents or caregivers) of patients between 2 and 6 years of age, of both sexes, who were diagnosed with cancer and were currently undergoing chemotherapy, in outpatient clinics or hospitalised. Criteria for exclusion, any patients and/or proxies with significant neuropsychiatric disorders and/or those with visual impairment that prevented them from viewing the assessment instruments. Patients were recruited as inpatients or outpatients. The researchers, respecting individuality, conducted the interviews. Participants were invited to complete the SSPedi-BR and PedsQL questionnaires.

\section{Study site}

The study was conducted in the children and youth cancer unit at the Barretos Cancer Hospital (Barretos, São Paulo, Brazil), a reference hospital in Latin America for cancer treatment.

\section{Patient and public involvement statement}

Patients and/or the public were not involved in the design or planning of the study. 


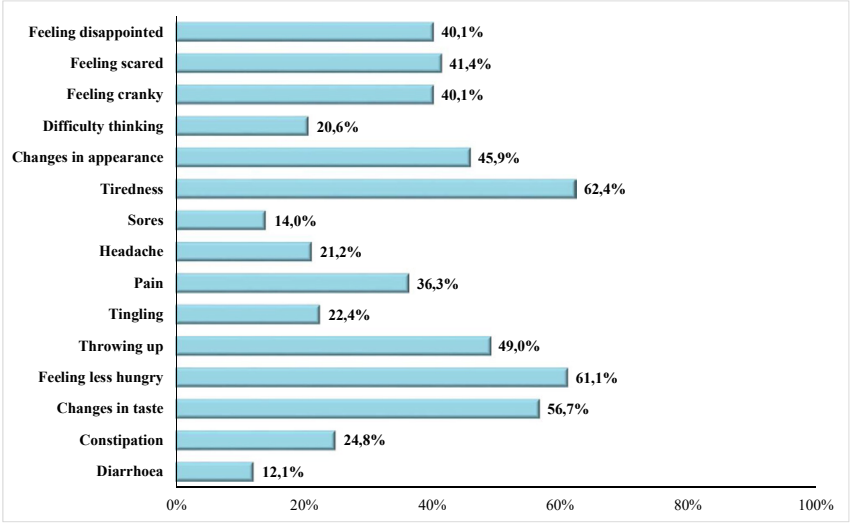

Figure 1 Prevalence (\%) of symptoms reported by patients by Symptoms Screening in Pediatrics, $(n=157)$. Axis $x$ : prevalence (\%); axis y: symptoms.

\section{Instruments for data collection}

Symptom Screening in Pediatrics Tool

SSPedi-BR is a recently translated and culturally adapted version of SSPedi, a self-report scale developed for symptom screening in paediatric patients with cancer between 8 and 18 years of age and can be applied as a proxy-reported version (parents or guardians).

Fifteen symptoms are rated using a 5-point Likert response scale (0-4) ranging from not at all bothered to extremely bothered. Patients respond to how much each symptom bothered them yesterday or today. Its original version is available in both paper and electronic versions. ${ }^{16-18}$

Assessment of psychometric properties into Brazilian Portuguese was performed using the paper version. The construct validity was tested according to the convergent validity and contrasted groups. The correlation values of the coefficients were considered good $(r \geq 0.4)$. The reliability was assessed using Cronbach's alpha test, internal consistency values of $\alpha=0.77$ (95\% CI 0.70 to 0.82 ) for the self-reported version, $\alpha=0.81$ (95\% CI 0.71 to 0.88 ) for the proxy-reported version. Thus, demonstrating the reliability and validity of this scale in daily clinical practice for the screening of multiple symptoms, it was renamed SSPedi-BR. ${ }^{18}$

\section{Pediatric Quality of Life Inventory 4.0}

PedsQL is a generic questionnaire that assesses QoL across paediatric chronic conditions. This scale consists of 23 items covering four domains: physical (8 items), emotional (5 items), social (5 items) and school functioning (5 items). The response scale has five levels ranging from 0 (never a problem) to 4 (almost always a problem). The scales are multidimensional, consisting of parallel self-report forms for the child or adolescent and a form for the parents. The response scale has five levels ranging from 0 (never a problem) to 4 (almost always a problem). The responses are inverted and transformed into $100,75,50,25$ and 0 , respectively, resulting in a scale range of $0-100$ in which a higher score indicates a better QoL. ${ }^{19}$
The psychometric properties of the Brazilian version of the PedsQL generic questionnaire proved to be valid and reliable. ${ }^{20}$

\section{Patient identification questionnaires}

Data were obtained from the patients' medical records. Sociodemographic information (sex, age, collection site, date of birth) and clinical information (date of diagnosis, primary tumour, distant metastasis and type of treatment) were also collected.

\section{Statistical analysis}

The sample size selected was estimated based on validation studies of other health instruments, which take into consideration between 3 and 20 times the number per research item. ${ }^{21}$

Sample characterisation was performed based on frequency tables. The association of characteristics (predominance and severity of symptoms) was analysed using the $\chi^{2}$ or Fisher's exact test, the multivariate logistic regression analysis and used the estimated coefficients to estimate the OR; variables with $\mathrm{p}<0.20$ in the univariate analysis were selected. The relationship between characteristics and SSPedi-BR symptoms and the PedsQL score was analysed using the Multivariate Analysis Of Variance (MANOVA) model (Pillai's trace) following the post-hoc test (Bonferroni). However, the scores under the domain 'school' were not considered for the proxy-reported version because this domain did not apply to the majority of our patients. To calculate the effect size (Cohen test (d)) of the differences between means of the two independent groups we used the $\mathrm{G}^{*}$ Power V.3.1.9.2 software.

The characteristics evaluated that are associated with the severity of symptoms were sex, primary tumour, time since diagnosis, distant metastasis, treatment preformed and amputation. Symptom severity was classified as low ('not bothered' to 'slightly bothered') and high ('very bothered to extremely bothered'). To calculate the SSPedi-BR score, the scores were summed to a total score ranging from 0 to 60 points. For analysis of the most prevalent symptoms, patients were classified into age groups (8-10, 11-14 and 15-18 years).

The significance level adopted was $5 \%$, and the analyses were performed using IBM SPSS V.21.0 software.

\section{RESULTS}

Between June 2017 and April 2018, 164 individuals were invited to participate in the study, with 7 participants refusing to participate because they were not feeling well at the time of the interview. The remaining 157 individuals were eligible, with 116 participants completing the self-reported version (patients between 7 and 18 years of age) and 41 the proxy-reported version (parents or guardians of patients between 2 and 6 years of age).

The sociodemographic and clinical characteristics of the participants are described in table 1. 
Table 2 Univariate and multivariate analyses of clinical characteristics associated with symptom severity

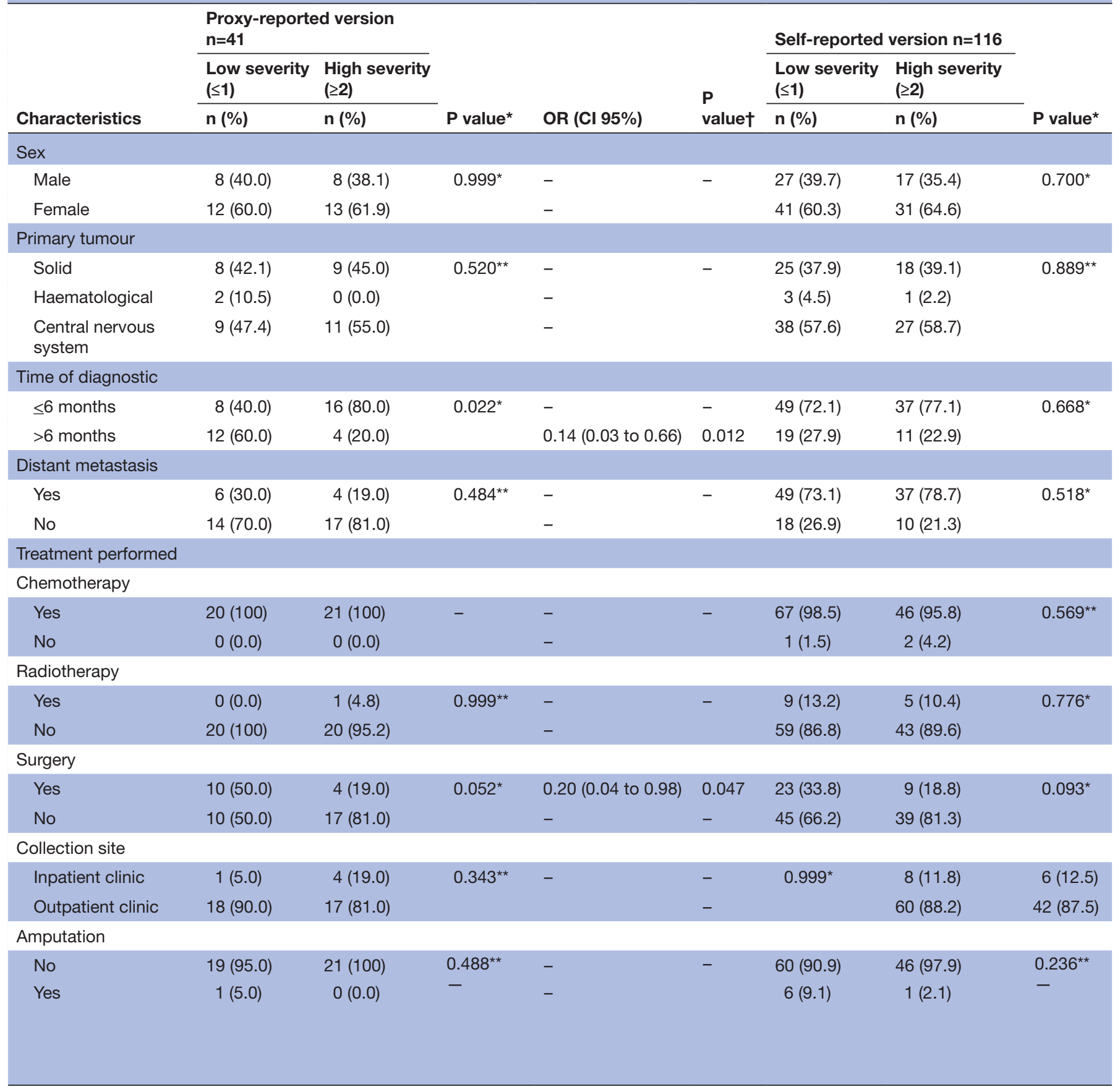

*Univariate analysis using ${ }^{*}$ Pearsons Chi-square and "*Fisher exact tests. p-value $<0.2$.

†Multivariate logistic regression analysis. $p$ value $<0.05$ Wald test.

\section{Prevalence of symptoms}

The most prevalent symptoms of the 157 participants were 'feeling tired'(98, 62.4\%), 'feeling more or less hungry (do not feel like eating) than you usually do' $(96,61.1 \%)$, 'changes in taste (flavour of the food)' (89, $56.7 \%$ ), 'throwing up or feeling like you may throw up' $(77,49 \%)$ and 'changes in how your body (visually) or face looks' (72, $45.9 \%$ ) (figure 1).

For the self-reported version of all age groups (8-10, 11-14 and 15-18 years), the most prevalent symptoms were 'changes in how your body (visually) or face looks' (31, 64.6\%, $\mathrm{p}=0.001)$, 'feeling tired' $(36,75 \% \mathrm{p}=0.005)$ and 'mouth sores' $(13,27.1 \%, \mathrm{p}=0.007)$ however, for the 15-18 years of age group there was a significant impact based on the increase in the frequency of symptoms reported.

\section{Severity of symptoms}

The data in table 2 illustrate the relationship between clinical characteristics and symptom severity, in association 


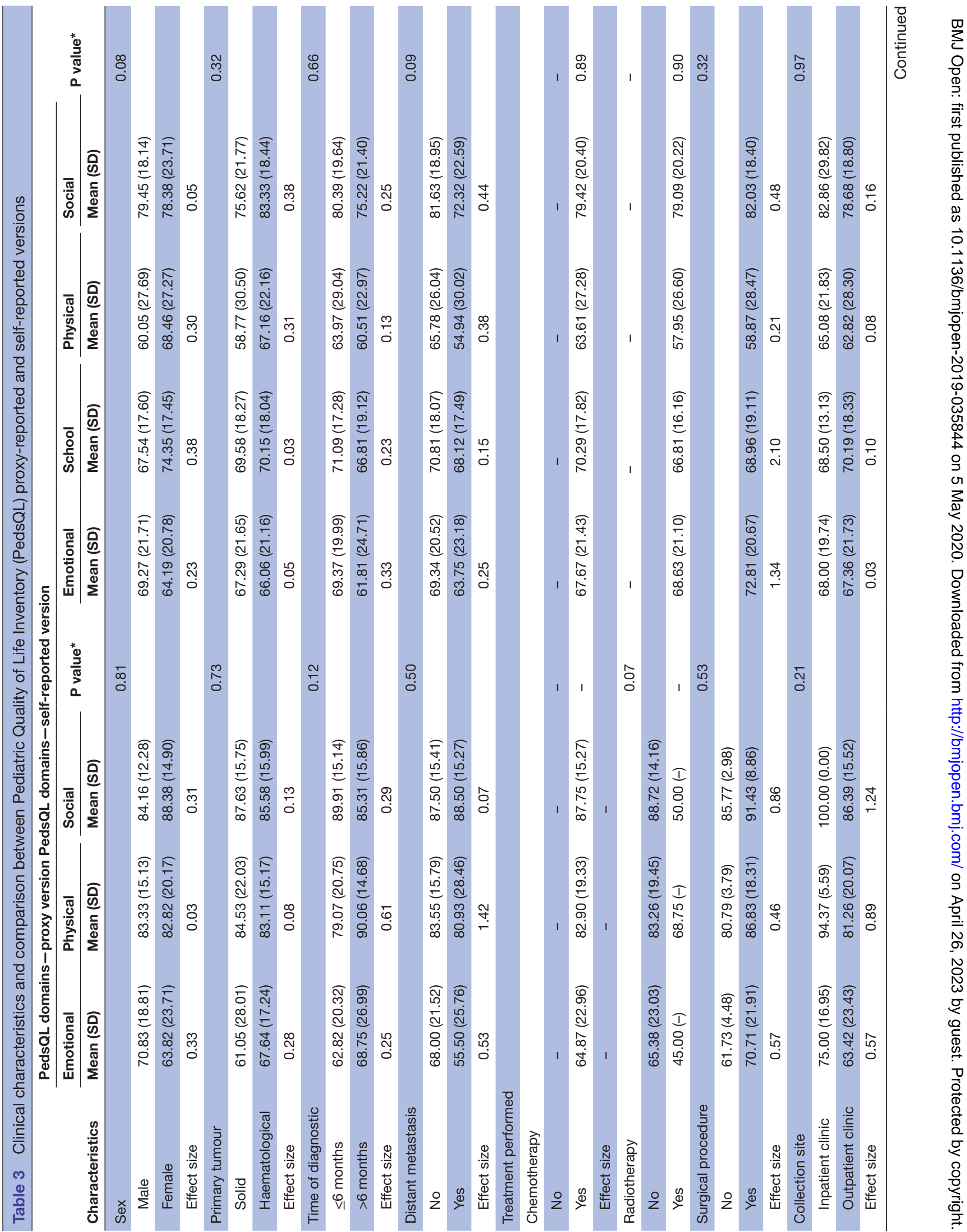


with the time of diagnosis and completion of surgical procedure.

\section{Clinical characteristics and PedsQL}

An analysis of the clinical characteristics associated with the PedsQL demonstrated no significant difference in any of the domains evaluated (table 3 ).

\section{Relationship between the symptoms of the SSPedi-BR scale and} PedsQL

In the self-reported version the following symptoms: 'feeling disappointed or sad', 'feeling scared or worried' (reflective) and 'feeling cranky or angry' (do not feel like smiling), presented a negative effect on QoL in the emotional domain. The symptoms of 'mouth sores' and 'constipation' (hard to poop) presented a negative effect in the school domain. The symptoms of 'hurt or pain' (other than a headache) and 'throwing up' or 'feeling like you may throw up', had an effect on the emotional and physical domain. A compelling finding was the identification of the symptom 'feeling tired' which had an impact on QoL of all four of the domains (emotional, school, physical, social) (table 4).

The only symptom in the proxy-reported version that had an influence on QoL was that of 'feeling scared or worried' resulting in a negative effect on the emotional domain (table 5).

\section{DISCUSSION}

The present study provides a comprehensive analysis of the multiple symptoms reported by paediatric patients with cancer in Brazil and the influence these symptoms have on the QoL of Brazilian paediatric patients. Through the use of the symptoms screen scale SSPedi-BR, it was possible to identify symptom prevalence, and severity experienced by patients while undergoing cancer treatment. In addition, this study identified the negative effect these symptoms had on QoL. This information can be beneficial for early intervention treatment based on the symptoms, resulting in a possible improvement in the QoL.

The results showed that during chemotherapy treatment, symptoms such as tiredness, lack of appetite, changes in taste, vomiting and change in physical appearance were the symptoms most reported by patients. These findings are consistent with a study describing symptoms using the original SSPedi screening tool, which identified the same symptoms as those that most bothered patients during treatment. ${ }^{22}$

There are several studies in the literature that assess symptoms and QoL in paediatric patients. ${ }^{2} 523$ For example, in their study on health-related QoL, Momani et $a l^{24}$ found that nausea, vomiting and fatigue were the most distressing symptoms reported by patients during treatment.

Symptoms differ among cancer types, treatments and age ranges. Adolescents with cancer are more emotionally 
Table 4 Symptoms of SSPedi-BR and comparison among the Pediatric Quality of Life Inventory scores $(n=116)$

\begin{tabular}{|c|c|c|c|c|c|}
\hline \multirow[b]{3}{*}{ SSPedi-BR symptoms } & \multirow[b]{3}{*}{ P value* } & \multicolumn{4}{|l|}{ Domains } \\
\hline & & Emotional & School & Physical & Social \\
\hline & & Mean (SD) & Mean (SD) & Mean (SD) & Mean (SD) \\
\hline No & 0.001 & $73.7(20.0)$ & $72.3(18.6)$ & $64.0(29.7)$ & $82.2(18.6)$ \\
\hline Yes & & $55.0(18.5)$ & $65.3(15.0)$ & $61.2(22.9)$ & $72.7(24.1)$ \\
\hline Effect size & & 0.98 & 0.41 & 0.22 & 0.4 \\
\hline \multicolumn{6}{|l|}{$\begin{array}{l}\text { Feeling scared or worried } \\
\text { (reflective) }\end{array}$} \\
\hline No & $<0.001$ & $74.7(19.5)$ & $71.3(17.3)$ & $63.3(27.8)$ & $77.7(22.7)$ \\
\hline Yes & & $55.7(19.2)$ & $67.8(18.4)$ & $62.6(27.3)$ & $81.2(15.2)$ \\
\hline Effect size & & 0.96 & 0.18 & 0.15 & 0.03 \\
\hline \multicolumn{6}{|l|}{$\begin{array}{l}\text { Feeling cranky or angry } \\
\text { (do not feel like smiling) }\end{array}$} \\
\hline No & $<0.001$ & $74.3(18.1)$ & $72.2(14.9)$ & $65.7(27.9)$ & $81.2(18.6)$ \\
\hline Yes & & $53.2(20.7)$ & $65.3(22.1)$ & $57.5(26.3)$ & $74.6(22.8)$ \\
\hline Effect size & & 1.12 & 0.35 & 0.38 & 0.41 \\
\hline$P$ value $e^{\star \star}$ & & $<0.001$ & 0.092 & 0.199 & 0.159 \\
\hline \multicolumn{6}{|c|}{ Problems with thinking or remembering things } \\
\hline No & 0.053 & $70.2(20.8)$ & $72.4(16.5)$ & $62.6(28.5)$ & $79.1(20.2)$ \\
\hline Yes & & $61.6(19.8)$ & $64.2(16.3)$ & $66.9(23.2)$ & $72.4(16.5)$ \\
\hline Effect size & & 0.65 & 0.49 & 0.08 & 0.22 \\
\hline$P$ value ${ }^{\star \star}$ & & - & - & - & - \\
\hline \multicolumn{6}{|c|}{$\begin{array}{l}\text { Changes in how your body } \\
\text { (visually) or face look }\end{array}$} \\
\hline No & $<0.001$ & $79.6(19.4)$ & $78.9(13.2)$ & $79.6(25.0)$ & $88.0(11.0)$ \\
\hline Yes & & $61.3(19.9)$ & $65.6(18.1)$ & $55.0(24.9)$ & $74.7(22.1)$ \\
\hline Effect size & & 0.85 & 0.83 & 0.78 & 0.49 \\
\hline$P$ value & & $<0.001$ & 0.001 & $<0.001$ & 0.004 \\
\hline \multicolumn{6}{|l|}{ Mouth sores } \\
\hline No & 0.019 & $68.6(21.6)$ & $73.0(17.4)$ & $65.0(26.9)$ & $80.2(21.3)$ \\
\hline Yes & & $62.1(20.2)$ & $56.6(12.3)$ & $54.4(29.1)$ & $73.7(13.6)$ \\
\hline Effect size & & 0.39 & 1.09 & 0.52 & 0.39 \\
\hline$P$ value ${ }^{\star *}$ & & 0.279 & 0.001 & 0.168 & 0.245 \\
\hline \multicolumn{6}{|l|}{ Headache } \\
\hline No & 0.072 & $71.0(21.2)$ & $72.3(16.4)$ & $65.2(27.6)$ & $80.7(19.9)$ \\
\hline \multirow[t]{2}{*}{ Yes } & & $57.8(19.4)$ & $62.8(19.4)$ & $57.2(27.6)$ & $74.1(20.7)$ \\
\hline & & 0.58 & 0.52 & 0.39 & 0.28 \\
\hline$P$ value ${ }^{\star \star}$ & & - & - & - & - \\
\hline \multicolumn{6}{|c|}{ Hurt or pain (other than headache) } \\
\hline No & 0.002 & $73.7(19.8)$ & $71.9(18.3)$ & $69.3(26.0)$ & $81.3(18.4)$ \\
\hline Yes & & $57.7(20.3)$ & $67.0(16.5)$ & $53.5(27.3)$ & $75.5(22.4)$ \\
\hline Effect size & & 0.73 & 0.27 & 0.64 & 0.23 \\
\hline
\end{tabular}




\section{Table 4 Continued}

\begin{tabular}{|c|c|c|c|c|c|}
\hline \multirow[b]{3}{*}{ SSPedi-BR symptoms } & \multirow[b]{3}{*}{ P value* } & \multicolumn{4}{|l|}{ Domains } \\
\hline & & Emotional & School & Physical & Social \\
\hline & & Mean (SD) & Mean (SD) & Mean (SD) & Mean (SD) \\
\hline$P$ value ${ }^{\star *}$ & & 0.001 & 0.216 & 0.008 & 0.198 \\
\hline \multicolumn{6}{|c|}{ Tingly (small shocks) or numb hands or feet (no feeling in the hands or feet) } \\
\hline No & 0.114 & $70.9(21.0)$ & $71.0(19.9)$ & $66.7(28.9)$ & $80.7(17.7)$ \\
\hline \multirow[t]{2}{*}{ Yes } & & $58.6(19.9)$ & $68.0(11.8)$ & $56.1(22.1)$ & $76.1(24.8)$ \\
\hline & & 0.71 & 0.17 & 0.56 & 0.26 \\
\hline$P$ value ${ }^{\star \star}$ & & - & - & - & - \\
\hline \multicolumn{6}{|c|}{ Throwing up or feeling like you may throw up } \\
\hline No & 0.033 & $73.8(21.7)$ & $74.7(16.5)$ & $68.8(22.3)$ & $81.8(20.6)$ \\
\hline Yes & & $61.8(19.6)$ & $65.8(17.9)$ & $58.0(30.6)$ & $76.6(19.6)$ \\
\hline Effect size & & 0.62 & 0.51 & 0.45 & 0.23 \\
\hline$P$ value ${ }^{\star \star}$ & & 0.009 & 0.02 & 0.068 & 0.232 \\
\hline \multicolumn{6}{|c|}{$\begin{array}{l}\text { Feeling more or less hungry } \\
\text { (change in appetite) than you usually do }\end{array}$} \\
\hline No & 0.425 & $72.0(23.2)$ & $69.5(17.8)$ & $63.4(31.2)$ & $78.8(20.1)$ \\
\hline Yes & & $64.3(19.6)$ & $70.2(17.8)$ & $62.8(24.9)$ & $79.2(20.4)$ \\
\hline Effect size & & 0.5 & 0.03 & 0.13 & 0.01 \\
\hline$P$ value ${ }^{\star *}$ & & - & - & - & - \\
\hline \multicolumn{6}{|c|}{ Changes in taste (taste of the food) } \\
\hline No & 0.448 & $70.5(22.3)$ & $71.8(13.1)$ & $62.9(28.1)$ & $78.1(19.5)$ \\
\hline Yes & & $64.7(20.3)$ & $68.3(20.9)$ & $63.2(26.5)$ & $79.8(20.9)$ \\
\hline Effect size & & 0.23 & 0.19 & 0.01 & 0.01 \\
\hline$P$ value ${ }^{\star \star}$ & & - & - & - & - \\
\hline \multicolumn{6}{|c|}{ Constipation (hard to poop) } \\
\hline No & 0.018 & 69.4. (21.4) & $73.7(13.9)$ & $66.0(26.9)$ & $80.8(20.3)$ \\
\hline Yes & & $61.5(20.4)$ & $59.0(22.9)$ & $53.3(28.0)$ & $73.8(19.2)$ \\
\hline Effect size & & 0.51 & 0.77 & 0.47 & 0.32 \\
\hline$P$ value ${ }^{\star *}$ & & 0.138 & 0.001 & 0.086 & 0.162 \\
\hline \multicolumn{6}{|c|}{ Diarrhoea (watery, runny poop) } \\
\hline No & 0.628 & $66.7(21.8)$ & $70.3(17.2)$ & $63.5(27.8)$ & 78.7 (20.6) \\
\hline Yes & & $73.7(15.7)$ & $66.2(23.1)$ & $58.2(25.7)$ & $82.5(19.4)$ \\
\hline Effect size & & 0.16 & 0.2 & 0.27 & 0.18 \\
\hline$P$ value ${ }^{\star \star}$ & & - & - & - & - \\
\hline Severity degree & $P$ value* & & & & \\
\hline Low & $<0.001$ & & & & \\
\hline \multicolumn{6}{|l|}{ High } \\
\hline Effect size & & 3.02 & 7.73 & 1.49 & 2.99 \\
\hline$P$ value $e^{\star \star}$ & & $<0.001$ & 0.037 & 0.035 & 0.296 \\
\hline
\end{tabular}

Self-reported version. *MANOVA (Pillai's trace), ${ }^{* *}$ post-hoc test (Bonferroni). SSPedi-BR, Rastreamento de Sintomas em Pediatria Brasileiro.

affected by physical symptoms. ${ }^{25}$ Additionally, changes in physical appearance are consequences of the adverse effects resulting from chemotherapy, explaining the low score often observed for this domain. ${ }^{26}$

In this study, the symptoms of changes in physical appearance, tiredness and mouth sores had a significant influence on patients 15-18 years of age (adolescent). These symptoms were among the most distressing factors and correlated with a worsening QoL. This result is in agreement with previous reports, in which the low QoL score of patients with cancer, especially tiredness, was most evident among adolescents when compared with other age groups. ${ }^{27}$

Among the presented symptoms, the most significant symptom is tiredness, affecting $50 \%-90 \%$ of the patients. In some cases, patients have reported this symptom 10 
Table 5 Symptoms of SSPedi-BR and comparison among the Pediatric Quality of Life Inventory scores ( $\mathrm{n}=41$ )

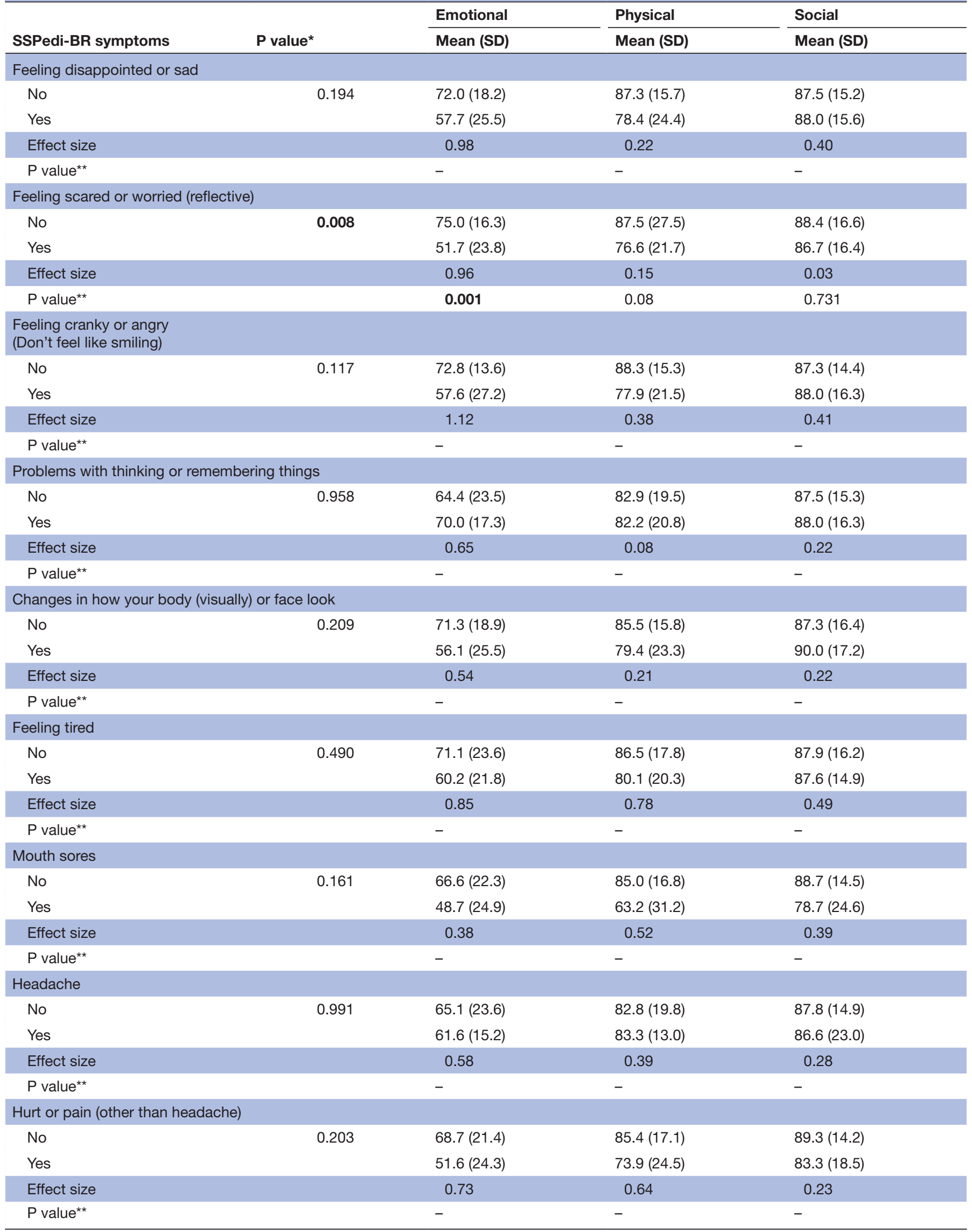


Table 5 Continued

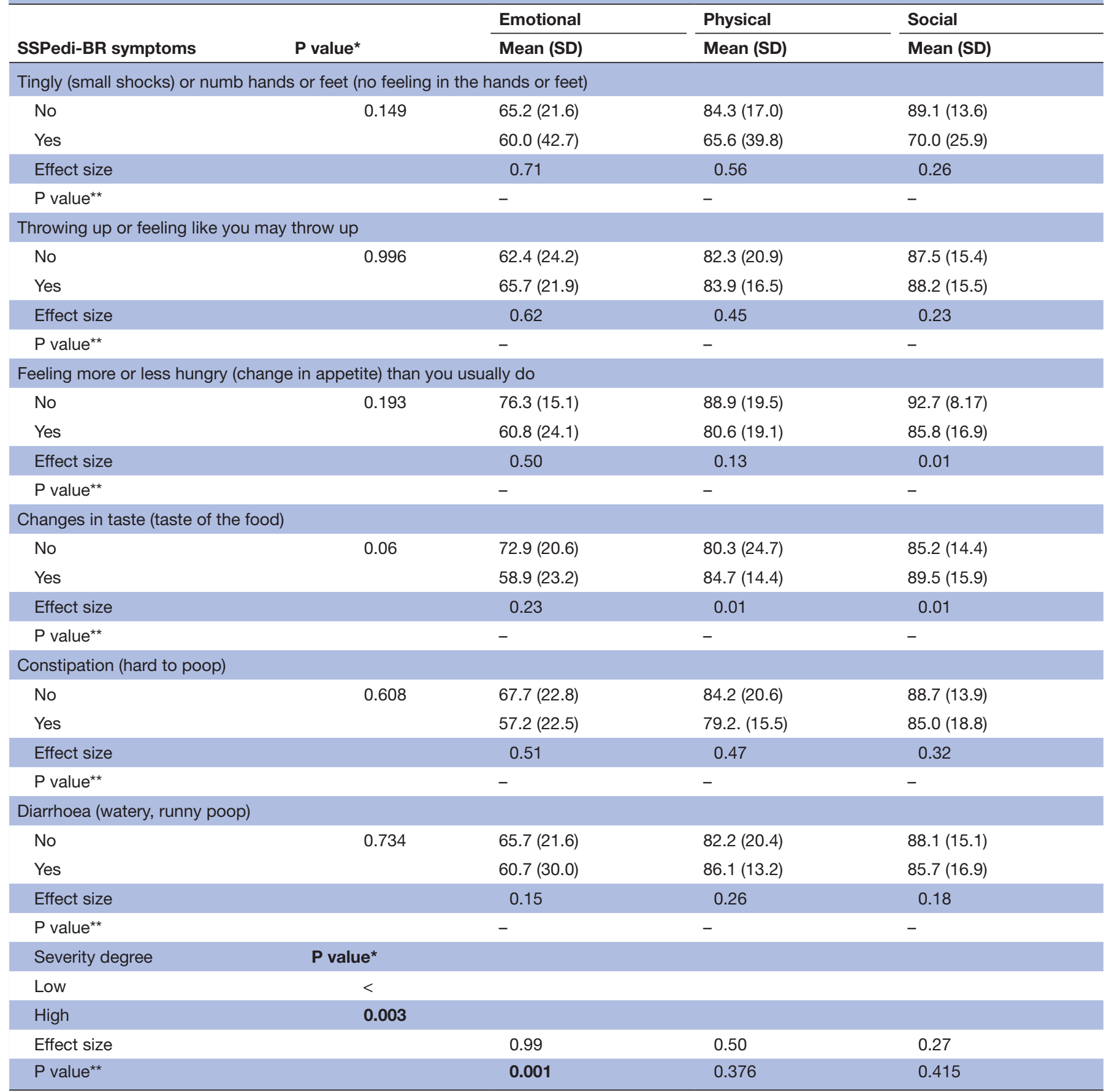

Self-reported version. *MANOVA (Pillai's trace), ** post-hoc test (Bonferroni). SSPedi-BR, Rastreamento de Sintomas em Pediatria Brasileiro.

years after the completion of treatment, thereby negatively influencing QoL. ${ }^{3}$

During treatment, patients may not report symptoms because they believe it is an inevitable adverse effect of treatment. Moreover, parents and professionals often do not report the problem, and consequently, the symptoms are not treated. ${ }^{28}$

Thus, understanding the characteristics, frequency, severity and how these symptoms affect the QoL of these patients may help in the development of strategies for the assessment, response and management during chemotherapy. ${ }^{25} 29$ Indeed, evaluation of QoL and specific measurement of symptoms have become essential in health services because they provide unique information that can assist in directing clinical interventions. ${ }^{30}$ Ultimately, improvements in the QoL of Brazilian paediatric patients can be achieved through the identification of association of symptoms displayed during treatment, that are often disregarded as a normal part of suffering during treatment. 
In the proxy-reported version, an analysis of the clinical characteristics and their association with symptom severity, the time since diagnosis $<6$ months was found to be related to higher severity of symptoms. This demonstrates that based on the perception of parents, patients present more symptoms at diagnosis, which leads to a worsening of QoL.

Although parent assessment is important when the child is not able to perform the assessment on their own, parents often project emotions based on their own experience and tend to overestimate symptoms. ${ }^{24}{ }^{31}$ This is evident as demonstrated in the results of this study in which the symptom of 'feeling scared or worried' was the only symptom to have a negative impact on the QoL for the emotional domain. No other symptom had a significant effect on QoL for any of the other domains as assessed by the parents.

The findings of the present study showed that clinical characteristics did not have a significant impact on any QoL. Furthermore, this study highlights the negative effects that symptoms have on QoL in all domains, with the greatest impact being in the emotional domain for both reported version. Few studies have identified factors that affect QoL in paediatric patients during chemotherapy, and most have been performed with paediatric cancer survivors, ${ }^{32}$ stressing the need to gain an early understanding of these symptoms during treatment.

These results indicate the importance for multiple symptom screening, that is quick and accurate, based on a patient's self-assessment, which will allow for the inclusion of a symptom-focused treatment plan for prevalent symptoms. The inclusion of proxies will enable clinicians in understanding the concerns of the primary caregivers; thereby, allowing clinicians to provide further clarification and information regarding symptoms.

A strength of the study that should be highlighted is the use of a recently validated and reliable symptom screening scale SSPedi-BR developed for the Brazilian Portuguese speaking paediatric population. This screening tool allowed for the identification of previously undocumented symptoms that have a negative influence on a patient's QoL within this population. However, future studies will benefit from longitudinal studies and a complete assessment of the changes of symptoms on QoL. In addition, the application of this screening tool in another treatment centre in Brazil may be necessary.

\section{CONCLUSION}

The present study shows that the prevalence of symptoms experienced among pediatric patients during treatment was high and significantly influenced all aspects of quality of life, especially in the emotional domain.

In addition, an assessment of clinical characteristics did not demonstrate any significant effect on QoL. These results demonstrate the importance of the use of instruments such as the SSPedi-BR in the management and control of symptoms during clinical practice.
Future studies of a longitudinal evaluation and assessment of the impact of symptoms on the QoL of patients at different stages of cancer treatment are needed.

Acknowledgements The researchers for this project would like to thank the Barretos Cancer Hospital internal research funds (PAIP) and the Epidemiology and Biostatistics Center of Barretos Cancer Hospital for assistance with the statistical analyses.

Contributors Design of study: SAC and BSRP. Drafting and reviewing questionnaires: SAC, BSRP and JOF. Acquiring data: SAC and JOF. Analysing data: MAd0, SAC, BSRP and CEP. Writing the manuscript: SAC, BSRP, JOF, MAdO and CEP.

Funding FAPESP - Fundação de Amparo à Pesquisa do Estado de São Paulo process 2017/01405-5.This study was financed in part by the Coordenação de Aperfeiçoamento de Pessoal deNível Superior - Brasil (CAPES) - Finance Code 88882.366201/2019-01

Disclaimer The content is solely the responsibility of the authors.

Competing interests None declared.

Patient and public involvement Patients and/or the public were not involved in the design, or conduct, or reporting, or dissemination plans of this research.

Patient consent for publication Parental/guardian consent obtained.

Ethics approval This study complied with the ethical and scientific principles of Resolution 466/12 of the National Health Council. The project was approved by the Research Ethics Committee of Barretos Cancer Hospital under protocol number 1508/2016. All participants or guardians provided informed consent or assent, as appropriate.

Provenance and peer review Not commissioned; externally peer reviewed.

Data availability statement All data relevant to the study are included in the article or uploaded as supplementary information. All data relevant to the study are included in the article or uploaded as supplementary information.

Open access This is an open access article distributed in accordance with the Creative Commons Attribution Non Commercial (CC BY-NC 4.0) license, which permits others to distribute, remix, adapt, build upon this work non-commercially, and license their derivative works on different terms, provided the original work is properly cited, appropriate credit is given, any changes made indicated, and the use is non-commercial. See: http://creativecommons.org/licenses/by-nc/4.0/.

ORCID iD

Bianca Sakamoto Ribeiro Paiva http://orcid.org/0000-0002-2711-8346

\section{REFERENCES}

1 Baggott C, Dodd M, Kennedy C, et al. Changes in children's reports of symptom occurrence and severity during a course of myelosuppressive chemotherapy. J Pediatr Oncol Nurs 2010;27:307-15.

2 Huang I-C, Brinkman TM, Kenzik K, et al. Association between the prevalence of symptoms and health-related quality of life in adult survivors of childhood cancer: a report from the ST Jude lifetime cohort study. J Clin Oncol 2013;31:4242-51.

3 Sung L, Zaoutis T, Ullrich NJ, et al. Children's Oncology Group's 2013 blueprint for research: cancer control and supportive care. Pediatr Blood Cancer 2013;60:1027-30.

4 Collins JJ, Byrnes ME, Dunkel IJ, et al. The measurement of symptoms in children with cancer. J Pain Symptom Manage 2000;19:363-77.

5 Abu-Saad Huijer H, Sagherian K, Tamim H. Quality of life and symptom prevalence in children with cancer in Lebanon: the perspective of parents. Ann Palliat Med 2013;2:59-70.

6 Rosenberg AR, Orellana L, Ullrich C, et al. Quality of life in children with advanced cancer: a report from the PediQUEST study. J Pain Symptom Manage 2016;52:243-53.

7 Sung L, Yanofsky R, Klaassen RJ, et al. Quality of life during active treatment for pediatric acute lymphoblastic leukemia. Int $J$ Cancer 2011;128:1213-20.

8 Souza JGS, Pamponet MA, Souza TCS, et al. Instrumentos utilizados $\mathrm{Na}$ avaliação dA qualidade de vida de crianças brasileiras. Revista Paulista de Pediatria 2014;32:272-8.

9 Sawada NO, Nicolussi AC, de Paula JM, et al. Qualidade de vida de pacientes brasileiros $\mathrm{E}$ espanhóis com câncer em tratamento 
quimioterápico: revisão integrativa dA literatura. Revista LatinoAmericana de Enfermagem 2016;24:2688.

10 Romero M, Vivas-Consuelo D, Alvis-Guzman N. Is health related quality of life (HRQoL) a valid indicator for health systems evaluation? Springerplus 2013;2:664.

11 Arslan FT, Basbakkal Z, Kantar M. Quality of life and chemotherapyrelated symptoms of Turkish cancer children undergoing chemotherapy. Asian Pac J Cancer Prev 2013;14:1761-8.

12 Pinheiro LC, McFatrich M, Lucas N, et al. Child and adolescent self-report symptom measurement in pediatric oncology research: a systematic literature review. Qual Life Res 2018;27:291-319.

13 Dupuis LL, Ethier M-C, Tomlinson D, et al. A systematic review of symptom assessment scales in children with cancer. BMC Cancer 2012;12:430.

14 Dupuis LL, Taddio A, Kerr EN, et al. Development and validation of the pediatric nausea assessment tool for use in children receiving antineoplastic agents. Pharmacotherapy 2006;26:1221-31.

15 FCd S, Thuler LCS. Tradução E adaptação transcultural de duas escalas para avaliação dA DOR em crianças $E$ adolescentes. $J$ Pediatr 2008:344-9.

16 Tomlinson D, Dupuis LL, Gibson P, et al. Initial development of the symptom screening in pediatrics tool (SSPedi). Support Care Cancer 2014;22:71-5.

17 Dupuis LL, Johnston DL, Baggott C, et al. Validation of the symptom screening in pediatrics tool in children receiving cancer treatments. $J$ Natl Cancer Inst 2018;110:661-8.

18 Cadamuro SdeA, Franco JO, Paiva CE, et al. Symptom screening in paediatrics tool for screening multiple symptoms in Brazilian patients with cancer: a cross-sectional validation study. BMJ Open 2019;9:e028149.

19 Varni JW, Seid M, Rode CA. The PedsQL: measurement model for the pediatric quality of life inventory. Med Care 1999;37:126-39.

20 Klatchoian DA, Len CA, Terreri MTRA, et al. Qualidade de vida de crianças E adolescentes de São Paulo: confiabilidade E validade $\mathrm{dA}$ versão brasileira do questionário genérico pediatric quality of life InventoryTM versão 4.0. J Pediatr 2008;84.

21 Mundfrom DJ, Shaw DG, Ke TL. Minimum sample size recommendations for conducting factor analyses. Int $J$ Test 2005;5:159-68.
22 Johnston DL, Hyslop S, Tomlinson D, et al. Describing symptoms using the symptom screening in pediatrics tool in hospitalized children with cancer and hematopoietic stem cell transplant recipients. Cancer Med 2018;7:1750-5.

23 Tha'er GM, Mandrell BN, Gattuso JS, et al. Children's perspective on health-related quality of life during active treatment for acute lymphoblastic leukemia: an advanced content analysis approach. Cancer nursing 2015;38:49.

24 Momani Tha'er G, Mandrell BN, Gattuso JS, et al. Children's perspective on health-related quality of life during active treatment for acute lymphoblastic leukemia: an advanced content analysis approach. Cancer Nurs 2015;38:49-58.

25 Baggott C, Cooper BA, Marina N, et al. Symptom assessment in pediatric oncology: how should concordance between children's and parents' reports be evaluated? Cancer Nurs 2014;37:252-62.

26 Lotfi-Jam K, Carey M, Jefford M, et al. Nonpharmacologic strategies for managing common chemotherapy adverse effects: a systematic review. J Clin Oncol 2008;26:5618-29.

27 Tomlinson D, Zupanec S, Jones $\mathrm{H}$, et al. The lived experience of fatigue in children and adolescents with cancer: a systematic review. Support Care Cancer 2016;24:3623-31.

28 Stenmarker E, Mellgren K, Matus M, et al. Health-Related quality of life, culture and communication: a comparative study in children with cancer in Argentina and Sweden. J Patient Rep Outcomes 2018;2:49.

29 Linder LA, Al-Qaaydeh S, Donaldson G. Symptom characteristics among hospitalized children and adolescents with cancer. Cancer Nurs 2018;41:23-32.

30 Eiser C, Varni JW. Health-Related quality of life and symptom reporting: similarities and differences between children and their parents. Eur J Pediatr 2013;172:1299-304.

31 Pöder U, Ljungman G, von Essen L. Parents' perceptions of their children's cancer-related symptoms during treatment: a prospective, longitudinal study. J Pain Symptom Manage 2010;40:661-70.

32 Pegoraro LGdeO, Gvozd R, Haddad MdoCFL, et al. Validation of instrument to assess software of patients' risk classification. Rev Bras Enferm 2018;71:975-82. 